\title{
The Impact of Increasing Input Costs to the Farmers in Cotton Production in Tanzania
}

\author{
Busheni Dome*, Dmitry Kuznetsov, Yaw Nkansah-Gyekye \\ Department of Applied Mathematics, The Nelson Mandela African Institution of Science and Technology (NM-AIST), Arusha, Tanzania
}

Email address:

domeb@nm-aist.ac.tz (B. Dome), dmitry.kuznetsov@nm-aist.ac.tz (D. Kuznetsov), yaw.nkansah-gyekye@nm-aist.ac.tz (Y. Nkansah-Gyekye)

To cite this article:

Busheni Dome, Dmitry Kuznetsov, Yaw Nkansah-Gyekye. The Impact of Increasing Input Costs to the Farmers in Cotton Production in Tanzania. Applied and Computational Mathematics. Vol. 4, No. 5, 2015, pp. 379-386. doi: 10.11648/j.acm.20150405.18

\begin{abstract}
The persistence of increasing input costs has effects to the farmers in the process of cotton production. These input costs can be in terms of pesticides, seeds, fertilizers, sprayers and the like, that have a real contribution towards cotton outputs per hectare. This paper intended to analyze effects of increasing input costs to the cotton farmers in Tanzania. The primary data were collected through questionnaires, which were distributed to 35 respondents, who are knowledgeable enough about cotton production in Shinyanga-Bariadi. Secondary data were collected from the Tanzania Cotton Board, Ukiliguru Agriculture Training Institute and Shinyanga Regional Commissioners. A log-linear model was estimated by using Panel data method consisting of 24 observations from Mwanza-Misungwi and Shinyanga-Bariadi from 2003 to 2014. The Hausman test was applied to evaluate the fixed effect and random effect by using STATA 11 and EXCEL. The elasticity for every variable was computed to evaluate how a change in input price might increase or decrease the costs to the cotton farmers in Tanzania.
\end{abstract}

Keywords: Input Costs, Elasticity (Coefficient), Cobb-Douglas, Cotton Farmers

\section{Introduction}

Cotton production is really sensitive to the fluctuations of input prices that result into decreased or increased costs and thus bringing about the strong effects in the life sustainability of cotton farmers and the national economy. Cotton producers in Tanzania face various reported problems including poor soil fertility, seed costs, pesticide costs, poor technology, and the like. However, in the 2008/2009 season, the rain fed cotton production average in Tanzania was about 700000 bales in the year, which is the same as 126000 MT of cotton lint. Moreover, the average income received by a farmer in 2008/2009 season was Tshs.304000 in the year per hectare. When this income is compared to the total costs of 174.2 USD, which is equivalent to Tshs.265655, the net profit earned by cotton farmers is almost negligible as it is about Tshs. 38345, which is too little amount earned per year [1]. Although the government of the United Republic of Tanzania (URT) through TCB gives input subsidies to the cotton farmers such as insecticides, the amount of these subsidies are still minimal compared with disincentives and nominal rates of assistance which normally remain insignificant when computed in respective years [2].

The authors in [3] applied the Cobb Douglas production function to analyze the data collected from input trend in cotton production in Pakistan. The study used a multiple linear regression to study the impact of individual input on total return and it was found that an individual input has positive correlation and it is statistically significant towards cotton outputs.

The author in [4] used the Cobb-Douglas production function to calculate the effects of variables (inputs) applied for the alfalfa production and in his study the results revealed that machinery variable has the most significant input which affects earning level of alfalfa production. The costs estimated by using the model are reliable, consistent, and significant for alfalfa yield as they facilitate to get total costs of production that is compared with the total output of production in order to obtain the net profit per hectare.

The authors in [5] used an econometric model of production to make estimation of inputs for kiwifruit production. The study using this model revealed that the parameters of human labour, machinery, total fertilizer, and water for irrigation have significant effects in improving the output of kiwifruit. Similarly, in cotton production the inputs mentioned are statistically significant towards contribution of cotton output to the farmers.

The correlation model was used to determine the 
relationship between cotton cultivation area and outputs. Their study found that there was no correlation as it showed that the correlation value is negative. Thus, the output obtained per unit area has direct effects on farmers from cotton production as the yields are insufficient to cover input costs used in production [6].

Moreover, the author in [7] used a multiple regression model to determine and evaluate the climatic effects on cash crop production for cotton and tea. The study observed that the model gives the high R-square value to indicate acceptability of a good model. Also, the study used a stochastic frontier model and observed that there is a good chance to maximize cotton production by increasing the technology.

The authors in [3] used a multiple linear regression model to study impact of each input on the cotton outputs. The findings indicated that the input costs can be increased over time and thus, if there is an increase of input costs in the process of production trend, the cotton farmers will move immediately to other competitive crop such as rice and sugar cane.

The author in [8] point out that policy amendment should be done towards reduction of transaction costs to the cotton farmers used in production causing effect to the farmers' demand for cotton inputs. Decreasing transaction costs can improve net profit to the cotton farmers.

Also, the author in [9] used the Cobb-Douglas production model in order to evaluate the contribution of education, land preparation, seed, irrigation, and the like towards the productivity of cotton in Punjab province of Pakistan. The study recommended that many of the factors such as years of schooling, irrigation, seed rate, plant production measures, and fertilizer nutrients have shown to support positively cotton production and therefore, the effects of these factors were noted to be significant.

The authors in [10] conducted a study to determine energy consumption and economic analysis of cotton production in Isfahan province of Iran. In their study, the Cobb-Douglas production function was used to assess the correlation between energy inputs and output, in which cotton output was assumed to be a function of human labour, machinery, diesel fuel, total chemical fertilizers, chemicals, farmyard manure, electricity, irrigation water, and seed. The results of this model revealed that cotton production in the area was not at the maximum in case of energy consumption.

The Cobb-Douglas production model was used to compare seedy watermelon production in full and reduced irrigation system in Iran in case of irrigation water energy use efficiency, energy budget, and economic analysis. The study found that labour force had the highest impact on seedy watermelon among other inputs based on the model with respect to costs. Similarly, the input costs have contributed much by labour force, which leads a strong effect to the cotton farmers to disengage effectively in cotton production [11].

The author in [12] used the Cobb-Douglas to analyse the sensitivity in groundnuts production and the study found that the elasticity of cost of production for labour force and seed was realized to be relatively high to show their significance in groundnuts production. In this case seed, fertilizer and labour force are the fundamental variables with respect to cost in production of any crop, which determine the outputs received by the farmers per hectare.

Cotton production is very important for the national economy as well as the alleviation of poverty to cotton farmers in Tanzania. The main outcry of cotton farmers is the rate of increasing input costs in cotton production. Most authors used the multiple regression, correlation, and CobbDouglas production model to study the impact of inputs and climate on total output in cotton production while one author used a stochastic model to study the chance of technology to maximize cotton production. All these studies did not provide real evidence about the impact of increasing input costs to the cotton farmers. Therefore, this paper aims to analyze the impact of increasing input costs to the farmers in cotton production in Tanzania.

\section{Materials and Methods}

The primary data were collected from 35 respondents in Shinyanga-Bariadi using questionnaires, these questionnaires were distributed to the respondents who possessed knowledge about cotton production. Secondary data were collected from the Tanzania Cotton Board, Ukiliguru Agriculture Training Institute and Shinyanga Regional Commissioners. The analysis of data was done using an econometric method, general statistics, and panel data. A loglinear model was estimated after taking out reasonable statistical test. In addition to that, elasticities were estimated by applying Ordinary Least Squares (OLS) in respect to the variables of a mathematical model enabled by STATA 11 and EXCEL.

\subsection{Econometric Model Clarification}

The econometric function was employed in order to point out the correlation between inputs required in the production of a particular crop and the output. Basically, the inputs needed in agriculture for production are mentioned as land, labour, and capital [13]. The production function for cotton was built by making use of the concepts of Cobb-Douglas production function. The model gives description to indicate the relationship between inputs and cotton output as written in the form

$$
W=f\left(Q, P_{i}, P_{l}, P_{c}, P_{t}\right)
$$

Where the Cobb-Douglas production function mathematically is written as

$$
Q=A \prod_{i=1}^{n} X_{i}^{\beta_{i}}
$$

$Q$ and $X_{i}$ represents output and inputs required in cotton 
production respectively. $A$ and $\beta_{i}$ are statistical parameters. The Cobb-Douglas production function can be modified and written according to input demand variables and parameters in cotton production as follows:

$$
W=Q^{\alpha q} B\left(P_{i}^{-z_{0}} P_{l}^{z_{1}} P_{c}^{z_{2}} P_{t}^{z_{3}} e^{\varepsilon}\right)
$$

where $\mathrm{W}=$ Amount of inputs demanded per hectare in respect to costs.

$P_{i}=$ Price of inputs,

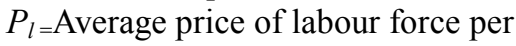

hectare,

$P_{c}=$ Price of cultivating cotton farm per

hectare,

$P_{t}=$ Price of transport per cart,

$\mathrm{Q}=$ Cotton output,

$\mathrm{B}=$ Constant return, and

$\alpha \mathrm{q}, z_{0}, z_{1}, z_{2}, z_{3}$ are the coefficients of the

variables after being expressed in log-linear equation.

Moreover, the study employed the Cobb-Douglas production model in the ground of theoretical and real situation for applied researches. The model was used in order to specify relationship between inputs and outputs in cotton production as a commercial crop in Tanzania. It has been applied in order to solve and make interpretation in respect to the cotton inputs required per hectare.

\subsection{Empirical Model}

A mathematical model in cotton production was formulated through total demanded inputs function with output, an average input price, labour force price, transport costs, and cultivation price.

Taking natural logarithm of both sides of equation (2), gives

$$
\operatorname{In} W=B+\alpha q \operatorname{In} Q-z_{0} \operatorname{In} P_{i}+z_{1} \operatorname{In} P_{l}+z_{2} \operatorname{In} P_{c}+z_{3} \operatorname{In} P_{t}+\varepsilon
$$

Thus, the equation (3) is log-linear as both dependent variable and independent variables respectively being narrated in form of natural logarithm and its coefficients are called elasticities.

\section{Results and Discussion}

\subsection{Descriptive Statistics of Panel data from 2003 to 2014}

Table 1. Statistical analysis of the Panel data for secondary data from 2003 to 2014.

\begin{tabular}{lllll}
\hline Variable & Obs & Mean & Std.Dev & Min \\
\hline Idemand (W) & 24 & 63225 & 8035.05 & 46000 \\
Output (Q)-Tshs/ha & 24 & 211039.2 & 218481.3 & 31280 \\
Labour (Wages-L)-Tshs/ha & 24 & 251500 & 53487.71 & 17500 \\
Transport (Tshs/cart)-T & 24 & 10187.5 & 4495.92 & 593000 \\
Cultivating costs (Tshs/ha)-C & 24 & 23645.83 & 5527.56 & 350000 \\
input price-Tshs & 24 & 131047.5 & 82348.14 & 15000 \\
Total costs (Tshs) & 24 & 348558.8 & 68755.79 & 47280 \\
Net profit (Tshs) & 24 & -137519.2 & 162866.4 & 242000 \\
\hline
\end{tabular}

From the statistical analysis in Table 1, it has been indicated that average output is 211039 and the total cost required for cotton production is averaged as 348559. Thus, the net profit is negative value of 137519. Input demand in respect to costs is 63225 required per hectare and input price is 131048 . This means that, higher input prices will increase total cost as the result cotton farmers receive little output per hectare because they fail to manage input costs. When the cotton outputs compared with the total costs used per hectare, it was revealed that a cotton farmer ends up with obtaining loss in the whole process of cotton production. This analysis provides evidence that, cotton farmers incur high inputs' costs in production and therefore the net profit received is almost negligible or they end up with loss in production.

Table 2. Correlation analysis of the Panel data.

\begin{tabular}{lllll}
\hline & $\begin{array}{l}\text { Idemand } \\
\text { (W) }\end{array}$ & $\begin{array}{l}\text { Output } \\
\text { (Tshs) }\end{array}$ & $\begin{array}{l}\text { Total costs } \\
\text { (Tshs) }\end{array}$ & $\begin{array}{l}\text { Net profit } \\
\text { (Tshs) }\end{array}$ \\
\hline Idemnd (W) & 1.0000 & & & \\
Output (Tshs) & 0.4967 & 1.0000 & & \\
Total costs (Tshs) & 0.8055 & 0.8633 & 1.0000 & \\
netprofit & 0.3263 & 0.9770 & 0.7359 & 1.0000 \\
\hline
\end{tabular}

Table 2 shows that there is less correlation between output received by cotton farmers and input demand in respect to costs as its value is 0.4967 . In addition to that, there is a strong correlation for total costs and inputs demanded as its value is 0.8055 . However, it is shown that there is a strong correlation for total costs and cotton output and its correlation value is 0.8633. Furthermore, there is less correlation between net profit and input demand in respect to costs as its value is 0.3263 and it is strongly correlated with cotton output and total costs as well. These results have been elucidated that the cotton output received by farmers mostly depends on inputs demanded per hectare. If the inputs' prices are very high, then it will cause cotton farmers to fail to apply inputs in cotton production as the result they will end up with poor output. This confirms the findings of the authors in [6] that the output obtained per unit area has a direct impact on farmers from cotton production as the yields are insufficient to cover input costs that used in production. The obtained correlation value of net profit and input demand for costs represents that the cotton farmers incur high input costs in production and thus the net profit received by cotton producers is almost negligible or sometimes incur loss in production. 


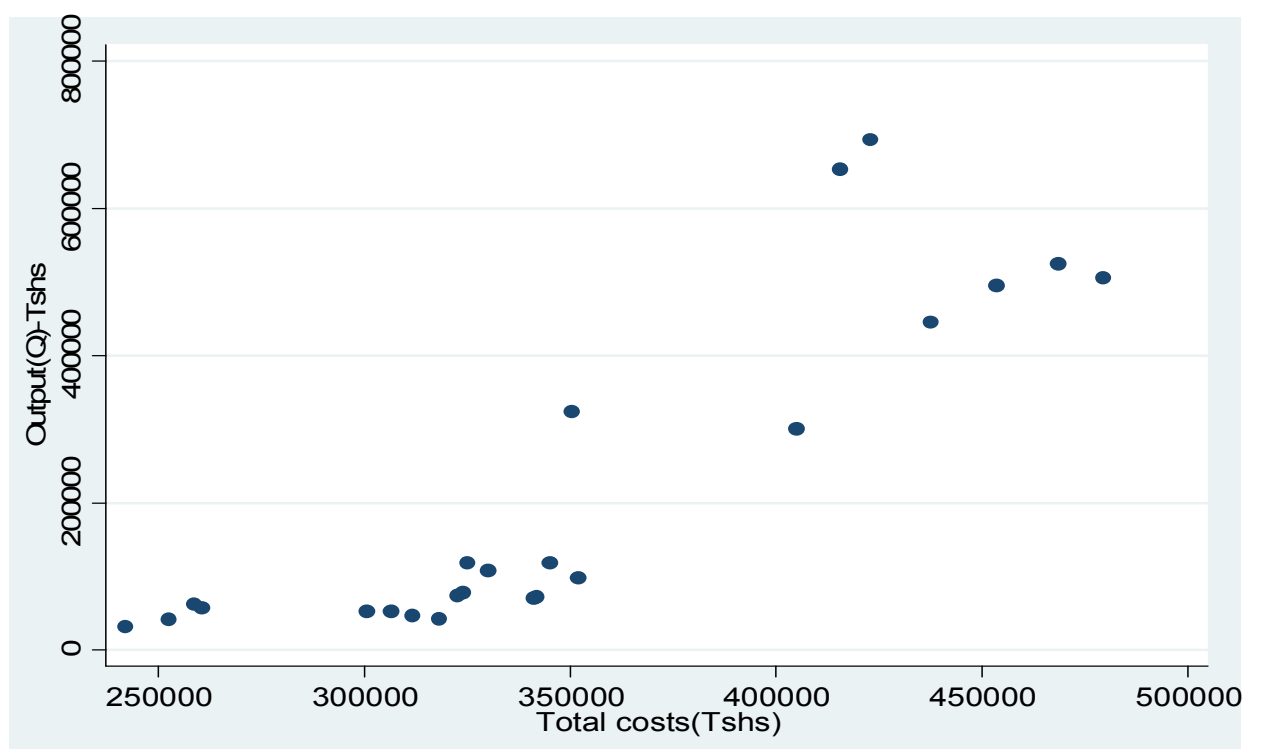

Figure 1. Correlation output (Tshs) and Total costs (Tshs) per hectare of Panel data.

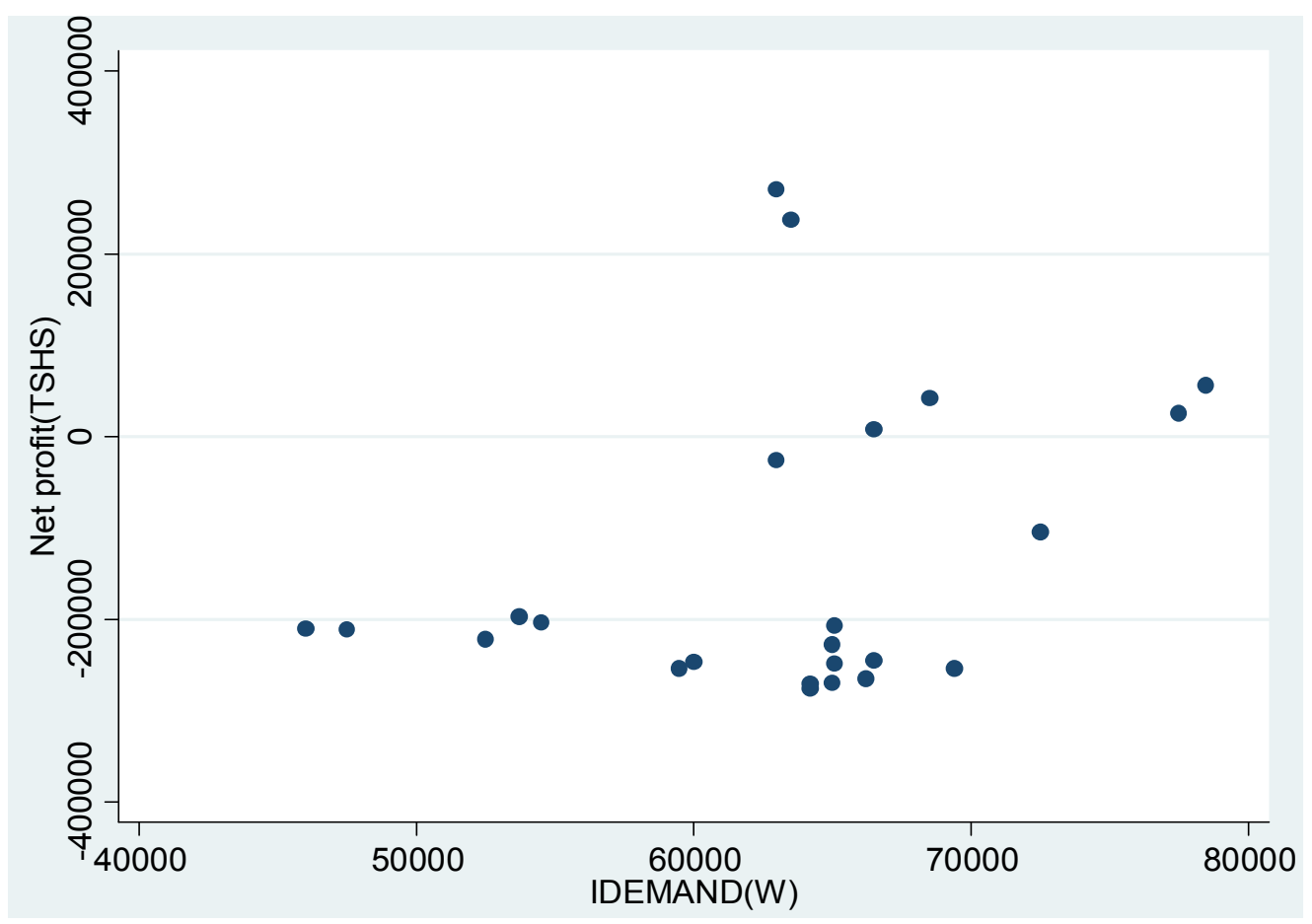

Figure 2. Correlation of Net profit (Tshs) and Input demand (Tshs) per hectare of Panel data.

Figure 1 indicates that there is a positive correlation between output and total costs while Figure 2 shows that there is less correlation as the most of points are scattered and have no specific direction.

\subsection{Regression Results}

A mathematical model was addressed in terms of input demand function with respect to input price, labour force (wage) price, cultivation price, transport price and cotton output acknowledged by farmers. The model was estimated by using Panel data method consisting of 24 observations from Mwanza-Misungwi and Shinyanga-Bariadi from 2003 to 2014. The Hausman test was applied to evaluate fixed effect and random effect by using STATA 11. It was revealed that input demand function of cotton production can be generated by applying random effect approach. The regression analysis results are as follows:

The log-linear variables were estimated using generalized least squares as indicated in Table 3 that adjusted (overall) $\mathrm{R}^{2}$ is 0.7235 , which shows that the variables in a mathematical model fit perfectly by $72.35 \%$. Thus, a mathematical model 
can be written as

Table 3. Regression analysis of panel data from 2003 to 2014.

\begin{tabular}{|c|c|c|c|c|}
\hline \multirow{2}{*}{\multicolumn{5}{|c|}{$\begin{array}{l}\text { Random effect GLS regression: Group variable: region } \\
\text { Dependent variable }\end{array}$}} \\
\hline & & & & \\
\hline $\begin{array}{l}\text { Independent } \\
\text { variable }\end{array}$ & Coefficient & Std.error & z-statistic & Prob $>\mid z$ \\
\hline B & 3.84 & 2.40 & 1.60 & 0.110 \\
\hline $\operatorname{LnP}_{i}$ & 0.04 & 0.11 & 0.35 & 0.730 \\
\hline $\mathrm{LnP}_{1}$ & 0.33 & 0.32 & 1.04 & 0.300 \\
\hline $\operatorname{LnP}_{c}$ & 0.28 & 0.17 & 1.69 & 0.091 \\
\hline $\operatorname{LnP}_{t}$ & 0.104 & 0.08 & 1.32 & 0.187 \\
\hline LnQ & -0.10 & 0.05 & -2.15 & 0.032 \\
\hline \multicolumn{5}{|c|}{ Cross-section fixed } \\
\hline & Within & 0.7220 & & \\
\hline \multirow[t]{2}{*}{ R-squared } & Between & 1.0000 & & \\
\hline & Overall & 0.7235 & & \\
\hline Wald Ch2(5) & 47.09 & & & \\
\hline Prob(F-statistic) & 0.000 & & & \\
\hline
\end{tabular}

$$
\begin{aligned}
& \operatorname{In} W=3.84+0.04 \operatorname{In} P_{i}-0.10 \operatorname{In} Q+0.33 \operatorname{In} P_{l} \\
& +0.28 \operatorname{In} P_{c}+0.104 \operatorname{In} P_{t}
\end{aligned}
$$

The findings have indicated that input price is 0.04 , which is positive and its interpretation stated that at $1 \%$ will lead to increase input demand in cotton production by $0.04 \%$ at $1 \%$ level. This means that cotton farmers are so sensitive to the changes of input price in increasing costs for demand input function of cotton production. Moreover, price for labour force, cultivation, and transport are $0.33,0.28$, and 0.104 responding statistically significant at $1 \%$ level. Thus, labour force, cultivation, and transport price are increasing by $1 \%$ respectively, which resulted into increasing input demand function for costs in the process of cotton production. This will cause cotton farmers to get loss in production as specified that elasticity for output is -0.10 . These results provide evidence that the price elasticity of inputs demanded in cotton production is positive. Therefore, this situation can cause cotton farmers make decision to shift to other commercial crops such as sunflower, cowpea, lentils, peanut stone, groundnuts, sesame and the like in order to produce and obtain output in the reasonable costs but with payable net profit. These results are similar to authors [3] and [1] stated that the net profit earned by cotton farmers is almost negligible due to increase of input costs over the time and thus there is existence of increasing of input costs in the process of production trend in which cotton farmers will move immediately to other competitive crops like rice and sugar cane.

\subsection{Descriptive Statistics of Primary Data}

Table 4. Statistical analysis of primary data in Shinyanga-Bariadi.

\begin{tabular}{llllll}
\hline Variable & Obs & Mean & Std.Dev & Min & Max \\
\hline $\begin{array}{l}\text { Output } \\
\text { (Tshs) }\end{array}$ & 12 & 337266.7 & 152117.8 & 178200 & 570000 \\
$\begin{array}{l}\text { Total costs } \\
\text { (Tshs) }\end{array}$ & 12 & 274333.3 & 59802.45 & 198500 & 352000 \\
Netprofit & 12 & 62933.33 & 985542.83 & -41000 & 218000 \\
\hline
\end{tabular}

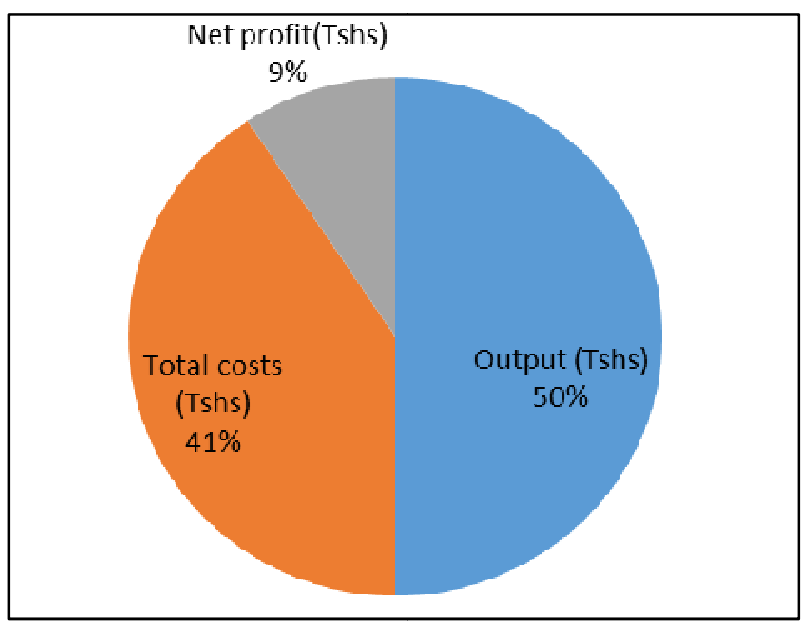

Figure 3. Pie chart of primary data.

Table 3 reveals that the average output of primary data is 337267 and an average total cost used in cotton production is 274333. The net profit obtained by finding the difference between the output and total costs used in cotton production is 62934. This is too little profit received by cotton farmers per hectare as the yearly income, which is almost insignificant because of higher input costs involved in the process of cotton production. Similarly, in Figure 3 shows that area is covered with outputs of about $50 \%$, followed by total costs of $41 \%$, while net profit is covered with an area of $9 \%$ to indicate that a farmer has received a small amount of profit per hectare in cotton production, probably due to tremendous input costs. These findings confirm that cotton farmers incur high costs in production and hence the cotton farmers receive poor net profit or loss in production. This can be a main factor for the cotton farmers to shift to other commercial crops. Therefore, in order to maximize the production of cotton for the farmers to receive reasonable profit, there should be some changes in cotton policy as what the author in [8] suggested.

Table 5. Costs and Outputs trends in Cotton Production.

\begin{tabular}{llll}
\hline Year & Output(Q)-Tshs & $\begin{array}{l}\text { Total } \\
\text { costs(Tshs) }\end{array}$ & $\begin{array}{l}\text { Net } \\
\text { profit(Tshs) }\end{array}$ \\
\hline 2003 & 41280 & 252500 & -211220 \\
2004 & 61680 & 258700 & -197020 \\
2005 & 53000 & 300500 & -247500 \\
2006 & 47080 & 311700 & -264620 \\
2007 & 78475 & 324000 & -245525 \\
2008 & 74165 & 322600 & -248435 \\
2009 & 117760 & 325100 & -207340 \\
2010 & 108000 & 330000 & -222000 \\
2011 & 324000 & 350500 & -26500 \\
2012 & 693000 & 423000 & 270000 \\
2013 & 495000 & 453500 & 41500 \\
2014 & 525000 & 468500 & 56500 \\
\hline
\end{tabular}

The data above can be represented in the following Figure:

Figure 4 shows that from 2003 to 2011 the total cost is above of the output received by cotton farmers in production while net profit from 2003 to 2011 is under the zero line. This revealed that, the cotton farmers received a loss in 
production and from 2012 onwards it demonstrates that farmers have obtained a small amount of net profit as the yearly income in respective periods of time. This confirms that the cotton farmers incur high costs in production. Thus, the strong effect of this situation may lead the cotton farmers to shift to other profitable crops because of high input costs required in cotton production.

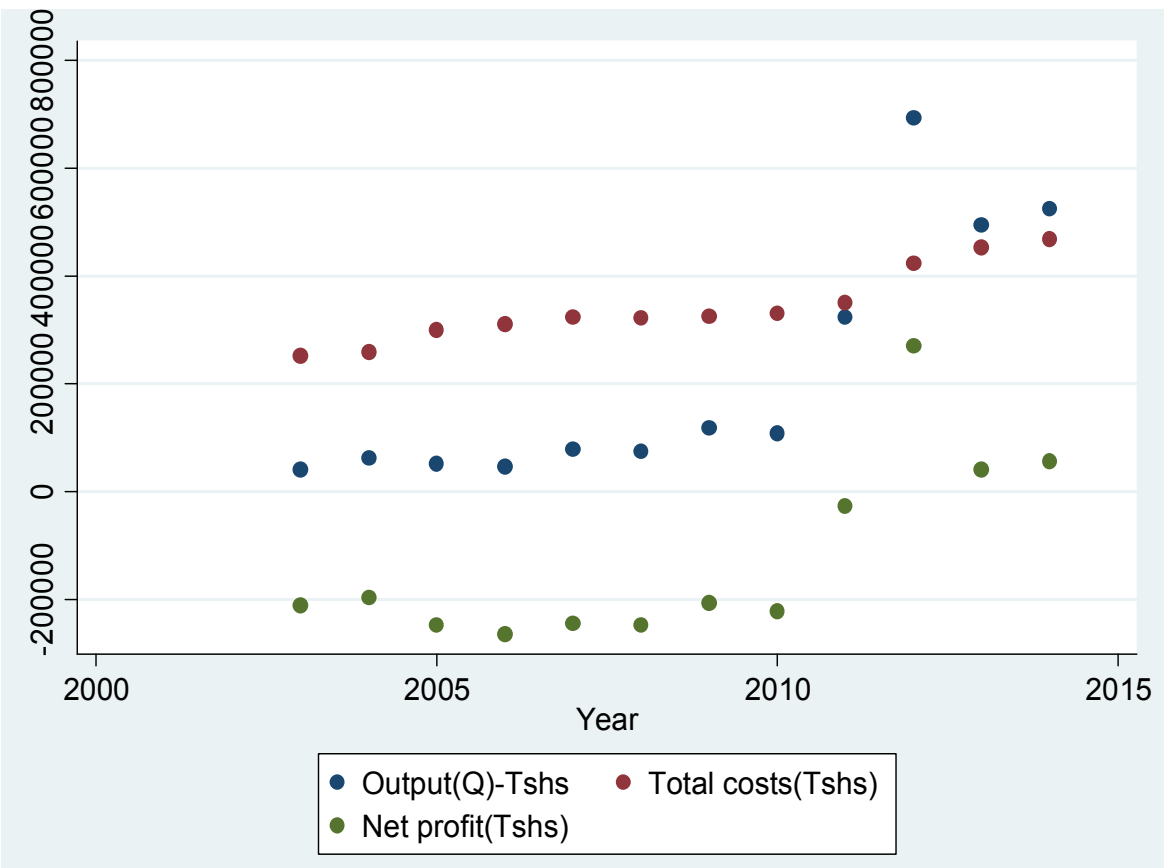

Figure 4. Statistical analysis of secondary data.

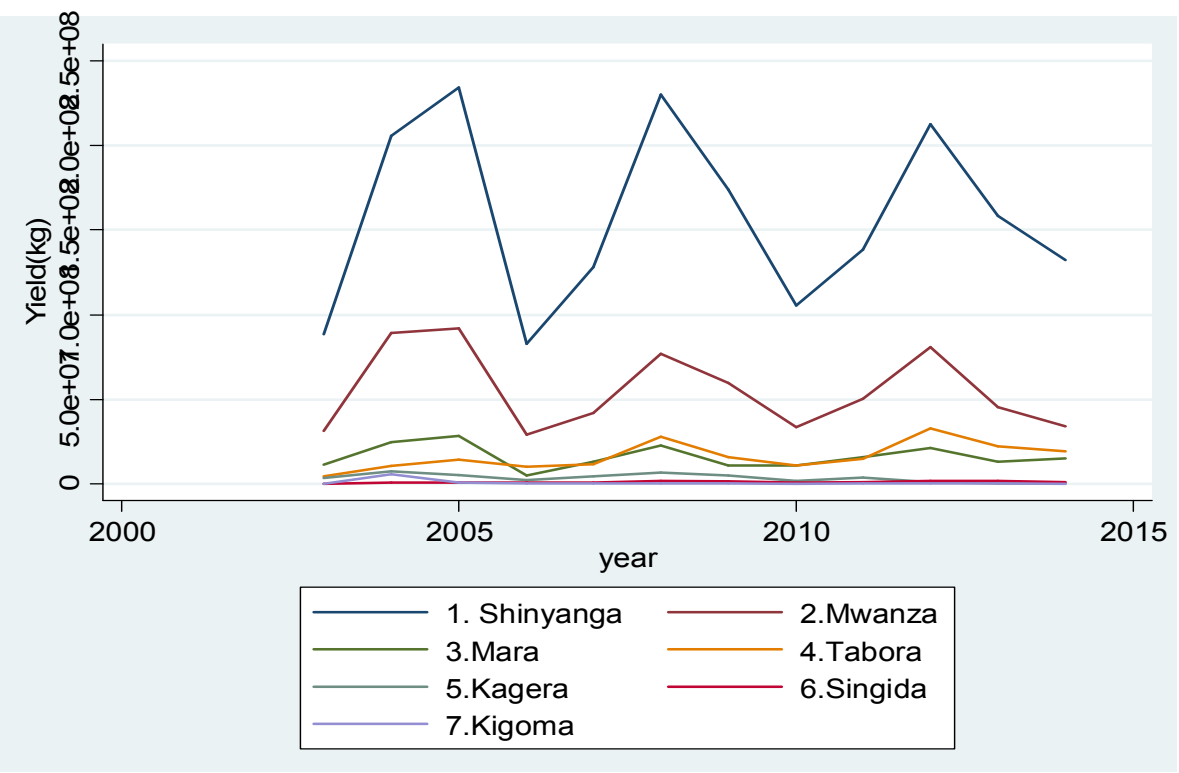

Figure 5. Cotton Production Trend for Ten (10) Seasons in WCGA from 2003-2014.

The fluctuation in cotton production may result from the increase in input costs under the assumption that there is no drought. This is shown in Figure 5 that from 2003 to 2005 cotton production increased for almost all regions in Western Cotton Growing Area (WCGA). The next season of 2006 cotton production decreased in all regions. However, from 2007 to 2008 cotton production increased again while in 2009 to 2010 cotton production decreased. Moreover, cotton production increased gradually from 2010 to 2012 and then dropped down up to 2014 .

This gives evidence that fluctuation in cotton production is due to higher changes in input costs that contribute to reduce cotton farmers' motivation. This provides the interpretation that cotton farmers need a huge amount of inputs which depends on input prices while the price given for the cotton seeds per kilogram in respective season is too little resulting into small net profit or loss sometimes. 


\section{Conclusions and Recommendations}

\subsection{Conclusions}

The analysis of a mathematical model revealed that there is a strong effect on increasing input costs to the cotton farmers in cotton production. Thus, it can be concluded from the observations that the cotton output average is Tshs. 211039 in a year per hectare and total cost is averaged to Tshs. 348559. However, the outcry of cotton farmers has been observed in terms of higher input costs which lead to a loss or negligible output of cotton as it is indicated that the elasticity of output is -0.10 , which is negative.

The negative value indicates that, cotton farmers undergo loss regularly in cotton production. In addition to that, there is less correlation between input demand function for costs and net profit, which is 0.3263 . This gives the meaning that the input costs used per hectare have less correlation with the net profit obtained by cotton farmers in a respective year as the net profit is almost negligible in cotton production.

\subsection{Recommendations}

The findings indicated that the cotton farmers incur higher input costs, thus there is a need to help cotton farmers to maximize and cover the losses in cotton production. The Ministry of Agriculture and Tanzania Cotton Board have an authority to help the cotton farmers to find a mechanism (means) for input costs to be minimized in order to generate reasonable net profit per hectare. This mechanism may be in terms of reduction of taxes and levies for the inputs required for cotton production.

The Ministry of Agriculture and Tanzania Cotton Board have the ability to find out immediately strategic methods within the country in order to promote and increase the price of cotton seed per kilogram to the cotton farmers instead of depending only on the world market. This could assist and motivate the cotton farmers to continue with the production of cotton seed because they will be comfortable with the market and the cotton price as well, instead of making a decision to shift to other commercial crops.

The establishment of strong cooperative society is very important to be emphasized because it helps to channel well to the cotton farmers. This cooperative society for cotton production make easy to provide education, advice, and guidelines practically in the field rather than in the meetings and workshops for good modernized agriculture. Thus, it will help farmers to earn profitable output in cotton production in the reasonable costs.

Also, there must be two way traffic of communications, that is, flowing information among of stakeholders such as local governments, TCB, TACOGA, Companies and Cooperative society, and the cotton farmers should be organized well by using technology such as mobile phones in order to share technics, expertise and ideas, particularly about the availability and distribution of inputs in the reasonable costs and the use of the planned methods of cotton inputs. Therefore, this helps to improve the outputs and life sustainability to the cotton farmers and the national economy as well.

\section{Acknowledgements}

The authors would like to express their sincere thanks to the administration of the Nelson Mandela African Institution of Science and Technology (NM-AIST) for sponsorship and permission to conduct this research.

\section{References}

[1] Tanzania Cotton Board, "The Seond Cotton Sector Development Strategy (CSDS II): 2009- 2015: A Stakeholder Roadmap for Increased Production,Productivity and Profitability of Cotton," Dar es salaam, March, 2010.

[2] FAO, "Analysis of Incentives and Disincentives for Cotton in the United Republic of Tanzania," MAFAP, Tanzania, January 2013.

[3] A. Hina, A. Muhammad, and A. Huma, "Economic Analysis of Input Trend in Cotton Production Process in Pakistan," Asian Economic and Financial Review 2(4):553-561, pp. 2(4):553-561, 2012.

[4] M. H. Ghasemi, "Economic Modeling and Sensitivity Analysis of the Costs of Inputs for Alfalfa Production in Iran: A case study from Hamedan province," Ozean Journal of Applied Sciences 3(3),, 2010.

[5] N. Banaeian, and M. Zangeneh, "Estimating Productio Function of Walnut Production in Iran using Cobb-Douglas Method," Agricultura Tropica Et Subtropica, p. Vol. 44 (4), 2011.

[6] E. I. Mwangulumba, and M.K. Buluma, "Tanzania Cotton Production and Productivity," A paper presented at the SEACF Conference in Nyeri-Kenya, 26th to 29 August 26th to 29 August 2012.

[7] M. A. Hamjah, "Climatic Effects on Cotton and Tea Productions in Bangladesh and Measuring Efficiency using Multiple Regression and Stochastic Frontier Model Respectively," Mathematical Theory and Modeling www.iiste.org, Vol.4, No.3, 2014.

[8] M. Barungi, J. Mugisha, I. Nalukenge, "Analysis of input demand by smallholder cotton producers in eastern Uganda," Eastern Africa Journal of Rural Development, pp. Vol.21,No.1, 2005.

[9] K. Bakhsh, I. Hassan, and A. Maqbool, "Factors Affecting Cotton Yield: A Case Study of Sargodha(Pakistan).," Journal of Agriculture \&Social Sciences, pp. Vol. 1, No. 4, 2005.

[10] M. Zahedi, H. E. Reza, and F. Mondani, "Energy Use Efficiency and Economical Analysis in Cotton Production System in an Arid Region: A Case Study for Isfahan Province, Iran," International Journal of Energy Economics and Policy, pp. Vol. 4, No. 1, pp.43-52, 2014.

[11] R. Moradi, P. R. Moghaddam, and H. Mansoori, "Energy Use and Economical Analysis of Seedy Watermelon Production for Different Irrigation system in Iran," Elsevier, Energy Report1 (2015), pp. 36-42, 2014. 
[12] A. D. Patience, "Profitability and Economic Efficiency of Groundnuts Production in Benue State, Nigeria," African Journal of Food, Agriculture, Nutrition and Development, pp. Vol.13, No.4, 2013.
[13] A. Michael, "Estimation of Irrigation Water Demand in Rice Production," IISTE, pp. Vol.4, No.7, 2014. 